\title{
CARACTERIZAÇÃO FÍSICA DE FRUTOS E SEMENTES DE GOIABA-DA- COSTA-RICA, PRODUZIDOS EM MANAUS, AMAZONAS ${ }^{1}$
}

\author{
ELIZABETHRODRIGUES REBOUÇAS ${ }^{2}$, DANIEL FELIPE DE OLIVEIRA GENTIL ${ }^{3}$, \\ SIDNEYALBERTODONASCIMENTOFERREIRA ${ }^{4}$
}

RESUMO-A goiaba-da-costa-rica (Psidium friedrichsthalianum) é uma espécie frutífera nativa da América Central, cultivada em pomares domésticos. Visando a contribuir para o estabelecimento de técnicas de implantação e condução de plantios comerciais, foi realizada a caracterização física de frutos e sementes dessa espécie. Assim, foi verificado que o valor médio da massa fresca dos frutos foi $42,19 \mathrm{~g}$, da polpa foi 39,72 $\mathrm{g}$ e das sementes foi 2,47g, com número em torno de 72,8 sementes por fruto. As sementes apresentam formato irregular, com valores médios de comprimento, largura e espessura de $4,29 \mathrm{~mm}, 4,11 \mathrm{~mm}$ e 2,68 mm, respectivamente. O fruto apresenta atributos favoráveis ao aproveitamento industrial, como o elevado rendimento em polpa (94\%) e o formato globoso, levemente achatado nos pólos (valor da relação diâmetro longitudinal/diâmetro transversal $=0,83$ ). $\mathrm{O}$ número elevado de sementes por fruto representa uma característica facilitadora à propagação e produção de mudas.

Termos para indexação: Myrtaceae, Psidium friedrichsthalianum, características biométricas, rendimento de polpa.

\section{PHYSICAL CHARACTERIZATION OF FRUITS AND SEEDS OF COSTA RICAN GUAVAS PRODUCED IN MANAUS, AMAZONAS}

\begin{abstract}
The Costa Rican guava (Psidium friedrichsthalianum) is a native fruit tree species of Central America cultivated in home gardens. The physical characterization of fruits and seeds of this species was done with the aim of contributing for the establishment of the implementation of techniques and commercial crops management. In this way, it was verified that the average fruit fresh weight was $42.19 \mathrm{~g}$, and pulp fresh weight was $39.72 \mathrm{~g}$, and seed fresh weight was $2.47 \mathrm{~g}$, with 72.8 seeds per fruit. The seeds are irregularly shaped, with average length, width and thickness of $4.29 \mathrm{~mm}, 4.11 \mathrm{~mm}$ and $2.68 \mathrm{~mm}$, respectively. The fruit presents favorable attributes for industrial exploitation, with high pulp yield (94\%) and a round shape, somewhat flattened on the apex and base (longitudinal diameter/transversal diameter ratio $=0.83$ ). The high seed number per fruit represents a characteristic that facilitates the propagation and seedling production of the species.
\end{abstract}

Index terms: Myrtaceae, Psidium friedrichsthalianum, biometric characteristics, pulp yield.

A espécie Psidium friedrichsthalianum (O. Berg) Niedenzu - Myrtaceae, conhecida no Brasil como goiaba-dacosta-rica e tendo como sinonímia botânica Calyptropsidium friedrichsthalianum (O. Berg), é encontrada naturalmente na Colômbia (especialmente no Cauca e vales de Magdalena), ao longo da América Central e ao redor de Oaxaca no México, em bosques pantanosos ao longo da costa e no interior; é cultivada em quintais de residências na Costa Rica e, ocasionalmente, em El Salvador, Guatemala e Equador (McVaugh, 1969; Morton, 1987).

A árvore alcança $6-10 \mathrm{~m}$ de altura e possui ramos avermelhado-escuros, levemente pubescentes quando jovens. O tronco é marrom-avermelhado com manchas acinzentadas. As folhas são opostas, simples, inteiras e glandulosas; o pecíolo mede 5-8 mm de comprimento; o limbo é elíptico, oblongo, elíptico-oblongo ou ovóide, medindo $5-12 \mathrm{~cm}$ de comprimento e 2,5-5cm de largura; o ápice é acuminado. As flores, normalmente isoladas, possuem coloração branca, cinco pétalas e, aproximadamente, 300 estames. O fruto é uma baga globosa que, quando madura, apresenta epicarpo de coloração amareloesverdeada e mesocarpo macio e esbranquiçado, com cheiro característico; a polpa é rica em pectina e apresenta $83,15 \%$ de umidade, $0,78-0,88 \%$ de proteínas, $5,75-6,75 \%$ de carboidratos, $0,39-0,52 \%$ de gorduras, $7,90 \%$ de fibras e $0,80 \%$ de cinzas. O consumo da polpa ao natural é limitado devido a sua acidez, mas pode ser utilizada na fabricação de bebidas refrescantes, geléias e doces (Famille, 1972; Morton, 1987).

O plantio comercial de fruteiras nativas tropicais é dificultado, em parte, pela escassez de informações que possibilitam a implantação de cultivos tecnificados. Assim, os resultados de estudos, como os de caracterização física de frutos e sementes, representam subsídios importantes ao estabelecimento de técnicas de produção de frutos comestíveis. A caracterização física de frutos, além de contribuir para a determinação de padrões de plantas em programas de melhoramento genético, pode fornecer informações para o

'(Trabalho 154-07).Recebido em: 19-06-2007. Aceito para publicação em: 14-12-2007.

${ }^{2}$ Engenheira Agrônoma, Bolsista DTI-1E/PPG7. E-mail:bethrodreb@yahoo.com.br.

${ }^{3}$ Professor, UFAM - FCA, Av. Gal. Rodrigo O. J. Ramos, 3000, Coroado I, 69077-000, Manaus, Amazonas. E-mail: dfgentil@ufam.edu.br.

${ }^{4}$ Pesquisador, INPA - CPCA, Caixa Postal 478, 69011-970, Manaus, Amazonas. E-mail:sanf@inpa.gov.br. 
manuseio e acondicionamento dos frutos, bem como para o dimensionamento da produção e de equipamentos a serem utilizados no processamento industrial da polpa (Carneiro, 1986a; Bosco et al., 1996). A caracterização física das sementes pode fornecer informações sobre a quantidade de frutos a serem colhidos e de sementes necessárias para fins de semeadura, sendo imprescindível no planejamento de produção de mudas. Diante disso, este trabalho teve por objetivo efetuar a caracterização física de frutos e sementes de goiaba-da-costa-rica (Psidium friedrichsthalianum), produzidos em Manaus, Amazonas.

O trabalho foi realizado no Laboratório de Sementes da Coordenação de Pesquisas em Ciências Agronômicas (CPCA) do Instituto Nacional de Pesquisas da Amazônia (INPA), em Manaus, Amazonas. Os frutos maduros (epicarpo com coloração amarelo-esverdeada), provenientes de doze plantas existentes no Câmpus do INPA-V8, foram colhidos no chão após a abscisão.

A caracterização física dos frutos foi efetuada em amostra de 100 unidades, que foram avaliadas individualmente considerando-se as seguintes variáveis: massa fresca do fruto, massa fresca da polpa (epicarpo + mesocarpo + endocarpo), massa fresca das sementes, diâmetro longitudinal do fruto, diâmetro transversal do fruto e número de sementes por fruto. A massa fresca da polpa foi obtida pela diferença entre a massa fresca do fruto e a massa fresca das sementes. As sementes de cada fruto foram extraídas com o auxílio de uma colher, lavadas em água corrente sobre peneira e secadas superficialmente em papel-toalha, antes da pesagem.

A caracterização física das sementes foi realizada em amostra de 100 sementes, que foram avaliadas quanto ao comprimento, largura, espessura e massa fresca. O peso de 1.000 sementes foi determinado, conforme Brasil (1992), em dez amostras de 100 sementes. As determinações foram feitas em paquímetro digital (sensibilidade de $0,01 \mathrm{~mm}$ ) e em balança digital (sensibilidade de 0,001g). Através dos dados, foram obtidas médias, desvios-padrão, valores mínimos e máximos e coeficientes de variação.

Os resultados da caracterização física dos frutos de goiaba-da-costa-rica estão apresentados na Tabela 1. A massa fresca média dos frutos foi de $42,19 \mathrm{~g}$, com valores mínimos e máximos de 18,02 g e 83,82 g, respectivamente. A polpa (epicarpo + mesocarpo + endocarpo) representou cerca de $94 \%$ da massa fresca do fruto, com valor médio de $39,72 \mathrm{~g}$. As sementes corresponderam acerca de $6 \%$ da massa fresca do fruto, com valor médio de $2,47 \mathrm{~g}$.

O rendimento em polpa, embora considerando que partes do fruto possam ser eliminadas no processo de despolpamento mecânico, é elevado quando comparado ao de frutos de outras mirtáceas. Em araçá-pêra (Psidium acutangulum) e cagaita (Eugenia dysenterica), o rendimento em polpa (epicarpo + mesocarpo) foi de 55,01-75,98\% (Andrade et al., 1993) e 80-87\% (Silva et al., 2001), respectivamente. Em cambuci (Campomanesia phaea), jambolão (Syzygium jambolana) e araçá-boi (Eugenia stipitata), o rendimento em polpa (apenas o mesocarpo) foi de 46,39-92,53\% (Vallilo et al., 2005), 60,8\% (Carneiro, 1986b) e 63\% (Ferreira, 1992), respectivamente.
O diâmetro longitudinal do fruto $(\mathrm{DL}=35,68 \mathrm{~mm})$ foi, em média, menor que o diâmetro transversal (DT $=42,90 \mathrm{~mm})$. Mesmo assim, o valor da relação diâmetro longitudinal/diâmetro transversal $(\mathrm{DL} / \mathrm{DT}=0,83)$ ficou próximo a 1 , indicando que o fruto, apesar de globoso, é levemente achatado nos pólos. Segundo Andrade et al. (1993), a relação DL/DT é um índice medidor da qualidade industrial, pois a forma do fruto é importante na definição das operações de processamento.

Os coeficientes de variação de diâmetro longitudinal $(12,72 \%)$, diâmetro transversal $(10,84 \%)$ e da relação DL/DT $(4,10 \%)$, indicaram que os dados observados nestas variáveis apresentaram distribuição mais homogênea (menos dispersa) do que os de massa fresca do fruto, da polpa e das sementes, cujos valores dos coeficientes de variação foram superiores a $30 \%$. Desse modo, sugerem que, para eficiência no processamento industrial, a variabilidade em massa fresca exigirá adequada seleção de plantas e/ou, classificação por massa após a colheita dos frutos. Os frutos de maior teor de massa fresca devem ser preferidos para industrialização, por apresentarem maior percentual de massa fresca de polpa e, por conseguinte, maior rendimento no processamento.

Os resultados da caracterização física das sementes de goiaba-da-costa-rica estão apresentados na Tabela 1. Os frutos apresentaram, em média, 72,8 sementes, com valor mínimo e máximo de 25 e 131 sementes, respectivamente. As sementes apresentam formato irregular, com valores médios de comprimento, largura e espessura de 4,29 $\mathrm{mm}, 4,11 \mathrm{~mm} \mathrm{e} \mathrm{2,68} \mathrm{mm,}$ respectivamente. A massa fresca média da semente foi de $0,03 \mathrm{~g}$ e o peso de 1.000 sementes (grau de umidade $=29,5 \%$ ) igual a $32,56 \mathrm{~g}$. Assim, pode-se estimar que um quilograma de sementes contenha, em média, 30.712,53 unidades e, com isso, deve-se considerar essas sementes como de tamanho pequeno, conforme Brasil (1992).

Por meio da análise de correlação (Tabela 2), foi verificada a associação significativa entre todas as características físicas dos frutos. As correlações foram positivas, sendo elevadas entre as variáveis massa fresca do fruto, massa fresca da polpa, diâmetro longitudinal do fruto e diâmetro transversal do fruto, significando que os frutos com maiores dimensões apresentam, normalmente, maior conteúdo de massa fresca e maior rendimento em polpa, e vice-versa. À exceção da massa fresca das sementes, as demais características apresentaram baixos níveis de associação com o número de sementes por fruto.

Diante disso, foi constatado que o fruto de goiaba-dacosta-rica apresenta atributos favoráveis ao aproveitamento industrial, como o rendimento em polpa de $94 \%$. O número elevado de sementes por fruto representa uma característica facilitadora à propagação e produção de mudas da espécie. 
TABELA 1 - Caracterísitcas físicas de frutos e sementes de goaibada-costa-rica (Psidium friedrichsthalianum), produzidos em Manaus, Amazonas.

\begin{tabular}{|c|c|c|c|c|}
\hline Característica & Média $^{1}$ & Valor mínimo & Valor máximo & CV (\%) \\
\hline \multicolumn{5}{|l|}{ Frutos } \\
\hline Massa fresca do fruto $(\mathrm{g})$ & $42,19( \pm 14,93)$ & 18.02 & 83.82 & 35.38 \\
\hline Massa fresca da polpa (g) & $39,72( \pm 14,47)$ & 16.07 & 79.59 & 36.42 \\
\hline Massa fresca das sementes (g) & $2,47( \pm 0,77)$ & 0.95 & 4.77 & 31.09 \\
\hline Diâmetro longitudinal $(\mathrm{mm})$ & $35,68( \pm 4,54)$ & 26.67 & 47.82 & 12.72 \\
\hline Diâmetro transversal $(\mathrm{mm})$ & $42,90( \pm 4,65)$ & 33.89 & 53.80 & 10.84 \\
\hline $\begin{array}{l}\text { Relação diâmetro longitudinal / diâmetro } \\
\text { transversal }\end{array}$ & $0,83( \pm 0,03)$ & 0.75 & 0.89 & 4.10 \\
\hline \multicolumn{4}{|l|}{ Sementes } & 33.96 \\
\hline Comprimento (mm) & $4,29( \pm 0,60)$ & 2.74 & 5.73 & 13.93 \\
\hline Largura (mm) & $4,11( \pm 0,46)$ & 3.22 & 5.23 & 11.20 \\
\hline Espessura (mm) & $2,68( \pm 0,26)$ & 1.97 & 3.57 & 9.62 \\
\hline Massa fresca (g) & $0,03( \pm 0,004)$ & 0.02 & 0.04 & 14.22 \\
\hline Peso de 1000 sementes (g) & $32,56( \pm 0,83)$ & 31.48 & 33.91 & 2.55 \\
\hline
\end{tabular}

\section{REFERÊNCIAS}

ANDRADE, J.S.; ARAGÃO, C.G.; FERREIRA, S.A.N. Caracterização física e química dos frutos de araçá-pêra (Psidium acuntangulum D.C.) Acta Amazonica, Manaus, v.23, n.2-3, p.213217, 1993.

BOSCO, J.; AGUIAR FILHO, S.P.; BARREIRO NETO, M.; MAIA NETO, J.S. Características físicas de frutos de gravioleiras cultivadas na Paraíba. Revista Brasileira de Fruticultura, Jaboticabal, v.18, n.1, p.85-91, 1996.

BRASIL. Ministério da Agricultura e Reforma Agrária. Regras para análise de sementes. Brasília: MARA/SNDA/DNDV/CLV, 1992.365p.

CARNEIRO, J.G.M. Estudos sobre a caracterização físico-química de frutos. I. Abiu (Lucuma caimito Roem \& Schult.). Revista Brasileira de Fruticultura, Jaboticabal v.8, n.2, p.35-40, 1986a.

CARNEIRO, J.G.M. Estudos sobre a caracterização físico-química de frutos. II. Jambolão (Syzygium jambolana DC). Revista Brasileira de Fruticultura, Jaboticabal, v.8, n.2, p.41-43, 1986b.
TABELA 2 - Coeficientes de correlação entre as caracterísitcas físicas de frutos de goaiba-da-costa-rica (Psidium friedrichsthalianum), produzidos em Manaus,Amazonas.

\begin{tabular}{|c|c|c|c|c|c|c|}
\hline Características & $\begin{array}{c}\text { Massa } \\
\text { fresca do } \\
\text { fruto }\end{array}$ & $\begin{array}{c}\text { Massa } \\
\text { fresca da } \\
\text { polpa }\end{array}$ & $\begin{array}{l}\text { Massa fresca } \\
\text { das sementes }\end{array}$ & $\begin{array}{c}\text { Diầmetro } \\
\text { longitudinal do } \\
\text { fruto }\end{array}$ & $\begin{array}{c}\text { Diâmetro } \\
\text { transversal do } \\
\text { fruto }\end{array}$ & $\begin{array}{c}\text { Número de } \\
\text { sementes por fruto }\end{array}$ \\
\hline Massa fresca do fruto & - & $0,99^{*}$ & $0,62^{*}$ & $0,96^{*}$ & $0,97^{*}$ & $0,43^{*}$ \\
\hline Massa fresca da polpa & - & . & 0,59 * & 0,96 * & 0,96 * & 0,39 * \\
\hline Massa fresca das sementes & - & - & - & $0,62 *$ & $0,64 *$ & 0,91 * \\
\hline Diâmetro longitudinal do fruto & - & - & - & 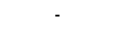 & 0,95 * & $0,45^{*}$ \\
\hline Diâmetro transversal do fruto & - & - & - & - & - & $0,42 *$ \\
\hline Número de sementes por fruto & - & - & - & - & - & - \\
\hline
\end{tabular}

*: significativo a $1 \%$ de probabilidade, pelo teste $\mathrm{t}$.

FAMILLE des myrtacées. Fruits, Paris, v.27, n.2, p.121-139, 1972.

FERREIRA, S.A.N. Biometria de frutos de araçá-boi (Eugenia stipitata McVaugh). Acta Amazonica, Manaus, v.22, n.3, p.295302, 1992.

McVAUGH, R. The botany of the Guayana highland. Part VIII, Myrtaceae. Memoirs of the New York Botanical Garden, New York, v.18, n.2, p.55-286, 1969.

MORTON, J. Costa rican guava Psidium friedrichsthalianum Ndz. In: MORTON, J. Fruits of warm climates. Miami: Creative Resource Systems, 1987. p.365.

SILVA, R.S.M; CHAVES, L.J.; NAVES, R.V. Caracterização de frutos e árvores de cagaita (Eugenia dysenterica DC.) no sudeste do Estado de Goiás, Brasil. Revista Brasileira de Fruticultura, Jaboticabal, v.23, n.2, p.330-334, 2001.

VALLILO, M.I.; GARBELOTTI, M.L.; OLIVEIRA, E.; LAMARDO, L.C.A. Características físicas e químicas dos frutos de cambucizeiro (Campomanesia phaea). Revista Brasileira de Fruticultura, Jaboticabal, v.27, n.2, p.241-244, 2005. 